\title{
Monitoring of Teachers' Views on Both CLIL and the Development of Pluriliteracies: A Longitudinal Qualitative Study
}

\author{
Xabier San Isidro ${ }^{1} \&$ David Lasagabaster ${ }^{1}$ \\ ${ }^{1}$ Faculty of Arts, English Studies Department, University of the Basque Country UPH/EHU, Vitoria-Gasteiz, \\ Spain \\ Correspondence: Xabier San Isidro, Faculty of Arts, English Studies Department, University of the Basque \\ Country UPH/EHU, Vitoria-Gasteiz, Spain.
}

Received: September 26, 2018 Accepted: January 5, 2019 Online Published: January 8, 2019
$\begin{aligned} & \text { doi: 10.5539/elt.v12n2p1 } \\ & \text { URL: https://doi.org/10.5539/elt.v12n2p1 }\end{aligned}$

\begin{abstract}
In Content and Language Integrated Learning (CLIL), the design of a language policy at school level is not only bound up with the number of languages used for learning and the number of hours devoted to teaching those languages, but also with the fact that language becomes specialised in relation to the subject, which impacts on the methodology used. These are the reasons for both language teachers and subject teachers to work together in design and implementation; and for the teachers' use of a translanguaging-based approach to language learning (San Isidro, 2018).

Previous research has dealt with teachers' opinions (Calvo \& San Isidro, 2012; Coonan, 2007; Infante et al., 2009; Pladevall-Ballester, 2015) on the difficulties of curriculum integration and its effects on both the different languages of instruction and the learning of content; or on the difficulties of language and content integration. However, methodology-oriented research on teachers' views and work in specific contexts is direly needed so as to gain a deep insight into the methodological commonalities that make CLIL what it is.

Our qualitative study is focused on a two-year monitoring of teachers' $(\mathrm{N}=6)$ views on CLIL implementation in a rural multilingual setting in Galicia. The teachers were monitored by means of interviews held between 2012 and 2014. After being trained, they took part in a CLIL project based on curriculum integration with two different groups of students. The findings reported showed that 1) teachers' initial views on CLIL implementation turned more positive over the two years; 2) teachers believed that CLIL provides a very good framework for the development of pluriliteracies; 3) their views regarding content learning in CLIL turned more neutral in the course of the two years; and 4) teachers stressed the need for methodology-oriented training.
\end{abstract}

Keywords: CLIL, views, pluriliteracies, curriculum integration, translanguaging

\section{Introduction}

\subsection{CLIL Implementation, a Pedagogical Approach}

Initially, in its originally European context, Content and Language Integrated Learning (CLIL) was "heralded as the potential lynchpin to tackle the foreign language deficit in our continent" (Pérez Cañado, 2016, p. 2), and, as such, in the course of more than two decades of implementation, it has adapted to the variegated contexts of the European language diversity and policies through various models in the different countries and regions (San Isidro, 2018). From a "well-recognised and useful construct for promoting L2/foreign language teaching" (Cenoz, Genesee, \& Gorter, 2013, p. 16), CLIL implementation has morphed into the design of language policies at school level, putting the spotlight on curriculum integration and the development of pluriliteracies along with remodelling teaching practice (San Isidro, 2018).

Since the very beginning, in terms of classroom implementation, the question of whether CLIL should be referred to as a methodology or an approach in pedagogical terms has been widely debated. Taking a look at the literature, it easily becomes apparent that the way CLIL is usually described is sometimes elusive, somewhat confusing and clearly lacking in consensus. When trying to conceptualise CLIL as an approach or a model, one easily comes across a multifaceted vision dependent on different perspectives - languages, content, culture, context, cognition, or technology - which makes it rather difficult to provide a straightforward definition. Marsh, Coyle, Kitanova, Maljers, Wolff, and Bronislawa (2005, p. 5) broadly described CLIL as a generic 
"umbrella" term to refer to "diverse methodologies which lead to dual-focused education where attention is given both to topic and language of instruction". This elusive definition of CLIL as an umbrella term used to refer to "diverse methodologies" was later revamped by Mehisto, Marsh, and Frigols (2008, p. 12) into the consideration of CLIL as an "umbrella term covering a dozen or more educational approaches".

The methodology-approach dilemma has been present in the literature from the very beginning of CLIL, in the mid 90s. Coyle (2007, p. 545) defined it as an "integrated approach where both language and content are conceptualised on a continuum without an implied preference for either". CLIL has also been said to refer to any dual-focused educational programme in which an additional language is used as a medium in the teaching and learning of non-language content. As Coyle, Hood, and Marsh $(2010$, p. 3) put it, "CLIL is an educational approach in which various language-supportive methodologies are used which lead to a dual-focused form of instruction where attention is given to both language and content". This last definition - general and wide-ranging as it is - points towards what the real issue is: CLIL cannot be considered a methodology, since it already comprises a set of methodologies.

More recent views on the question have added to further confusion over the matter. For instance, when explaining CLIL, Ball, Kelly, and Clegg $(2015$, p. 23) use "CLIL as a methodology" as a title for a section to later state that "CLIL (as a paradigm) shares an interface with a number of other approaches". Conversely, in their explanation, they make it clear that they consider CLIL an approach.

It is precisely because of this lack of consensus that some researchers deem CLIL conceptually vague (Bruton, 2013), and this is the reason for the need to untangle the approach-methodology conceptual knot. According to Hofler (2010, p. 71), an approach "can be defined as the basic philosophy or belief concerning the subject matter being considered. It is the set of assumptions or points of view held by individuals concerned with their field". Hofler (2010, p.71) goes on to conceptualise a method as "an overall, long-term orderly presentation of the material based on the approach. It is an orderly arrangement, its presentation is predetermined and it is systematic. Method is synonymous with such terms as system or programme". Considering both definitions, CLIL is clearly a set of assumptions and those assumptions (approach) can be arranged through an amalgamation of identifiable methodologies, which are related to the learning of languages and the learning of content.

According to San Isidro (2018), despite this conceptualisation appearing to be too broad or complex, there are many commonalities or assumptions that make CLIL identifiable as a set of educational classroom practices in the different contexts of the European continent:

- In CLIL programmes, the knowledge of the language becomes the means of learning content, i.e. language is integrated in the broad curriculum.

- CLIL is based on language acquisition rather than on language learning, since language is seen or is used in real-life situations in which students can acquire it. Learners develop fluency through use, through communicating for a variety of purposes.

- In CLIL, content is "fronted" (Ball et al., 2015, p. 37), i.e. it is prioritised.

- In CLIL, tasks are seen as a priority in relation to language becoming a means. At the same time, key language is made salient, i.e. language support is scaffolded as the language is subject to the patterns of task development.

- By the same token, the subject matter determines the language needed to learn and this brings about language academic specialisation - Cognitive Academic Language Proficiency, CALP (Cummins, 1984) - (e.g. Science-related, Math-related or Art-related). CALP-related accuracy also develops through use, in an incidental way, out of what students need to complete tasks.

San Isidro (2018) also states that, when implementing CLIL, i.e. when trying to provide an arranged and systematic methodology related to the assumptions above, teachers have to face the fact that it is not only about teaching languages, but also about using an additional language to learn content along with developing pluriliteracies. In other words, CLIL involves planning additional language learning in relation to the other languages of instruction, i.e. translanguaging; and it also involves focusing on the specialised subject-related language, i.e. meaning-making. To put it simply, teachers need to plan their translanguaging classroom practice with a view to developing the students' pluriliteracies. The design of a language policy at school level is not only bound up with the number of languages used for learning and the number of hours devoted to teaching those languages, but also with the fact that language becomes specialised in relation to the subject, which impacts on the methodology used. These are the reasons for both language teachers and subject teachers to work together in design and implementation, and for the teachers' use of a translanguaging-based approach to language learning 
(San Isidro, 2018).

Implementation-oriented research on teachers' views is direly needed so as to gain a deep insight into the methodological commonalities that make CLIL what it is. Paying attention to curriculum integration and translanguaging means considering teachers' perceptions and opinions as one of the sinews of research, as they - the teachers - hold the ultimate responsibility for curriculum and task design in CLIL. Previous research dealing with teachers' opinions (Calvo \& San Isidro, 2012; Coonan, 2007; Infante, Benvenuto, \& Lastrucci, 2009; Pladevall-Ballester, 2015) has been conducted in different contexts, dealing with teachers' opinions on the difficulties of curriculum integration and its effects on both the different languages of instruction and the learning of content; or on the difficulties of language and content integration.

Research studies have shown that stakeholders involved in CLIL show positive views and attitudes as well as higher motivation regarding the foreign language. According to Lasagabaster and Doiz (2017), researchers seem to agree that high levels of motivation are perceived among students and teachers: "one of the most powerful findings of CLIL groups centers on increased motivation in both learners and teachers" (Coyle, 2006, p. 11, as cited in Lasagabaster \& Doiz, 2017). Similarly, according to Lorenzo, Casal, and Moore (2010), studies into CLIL stakeholders' perceptions seem to have garnered positive views as far as foreign language learning is concerned.

Within the realm of qualitative analysis, Mehisto and Asser (2007) conducted a study into stakeholders' perspective (school principals, teachers and families) in Estonia using semi-structured interviews, questionnaires and lesson observation. Results showed high levels of satisfaction, commitment and engagement in all stakeholders. In a similar fashion, Wiesemes' (2009) study on students and teachers in 8 schools in the United Kingdom revealed that CLIL enhanced motivation.

In Austria, Ackerl (2007) used four types of lexical tests as well as questionnaires with learners and teachers involved in CLIL experiences. A greater intrinsic motivation of the CLIL students surfaced in the results together with teachers' satisfaction with CLIL practice.

Czura, Papaja, and Urbaniak (2009) analysed the outcomes resulting from a qualitative study on CLIL, based on classroom observation and interviews with students and teachers in Poland. Results revealed that teachers showed professional satisfaction as they felt more involved, committed and eager.

In Italy, Coonan (2007) used interviews, focus-group sessions and even teacher daily logs to analyse the perceptions of 33 secondary school teachers. Results showed that CLIL positively affected not only the way students learned content, but also their motivation and their degree of attention in lessons. Also in Italy, Infante et al. (2009) interviewed 11 experienced CLIL teachers using questionnaires and follow-up telephone conversations dealing with their professional background. Results showed that teachers' views on CLIL implementation were positive on the grounds of its effectiveness and methodological advantages.

Pladevall-Ballester's (2015) study provided an overview of the students', CLIL teachers' and parents' perceptions after a year of CLIL implementation in five primary schools in Catalonia, elicited by means of opinion-based questionnaires and interviews. Teachers' opinions offered a realistic picture of what CLIL in primary school involves. Despite their general satisfaction with the experience and their enthusiasm and hard work, teachers highlighted their concerns and frustrations, mainly derived from the lack of institutional and peer support along with the lack of time.

Regarding the Galician context, the one where our research took place, two studies (Barreiro \& San Isidro, 2009; Calvo \& San Isidro, 2012) focused on large-scale quantitative analyses of teachers' perceptions and students' results in secondary and primary education, respectively. In both studies, teachers' perceptions were really positive about students' attitudes and performance in the three languages and content learning. Nonetheless, both emphasised the need for long-term and small-scale analyses, which is exactly what our study accomplishes as it is focused on a longitudinal qualitative small-scale monitoring of teachers' views.

\subsection{The Context}

The context of this research is a multilingual one, within an Autonomous Community — Galicia - with two co-official languages, in which language provision regarding language policy has been an important issue by virtue of the recognition of minority languages both in the Constitution of 1978 and in the regional statutes. Language policy in Galicia has been based on a maintenance-development immersion provision as far as the Galician language is concerned. Regarding attitudes towards it and motivation to learn (through) it, this maintenance-development policy has run parallel to the attempts of overcoming the diglossic consideration of Galician as a low-prestige minority language (Loureiro-Rodríguez, Bogess \& Goldsmith, 2013; Nandi, 2017). 
Furthermore, from the late 90s on, CLIL has been gradually introduced in the curricular system on an experimental basis. Interestingly, the introduction of additional languages as vehicles for teaching non-linguistic curricular subjects has had a large effect on language policy design (Calvo \& San Isidro, 2012). Over the past few years, the Galician Educational Department has been trying to find the answer to the question of how to harmonise a language policy based on protection and preservation of Galician with the inclusion of other languages in the curriculum, in line with European guidelines on plurilingualism. In June 2010, a decree on Plurilingualism (Decree 79/2010) was published by the Educational Department, officially bringing an additional or foreign language as vehicular into public education, setting out that one third of subjects must be taught in a foreign or additional language - mainly English - with the two remaining thirds taught in the two co-official languages - Galician and Spanish- (San Isidro, 2017).

\subsection{The Study}

With the context above in mind, this article presents a longitudinal qualitative study focused on a two-year monitoring of teachers' $(\mathrm{N}=6)$ views on CLIL implementation in a rural multilingual setting in Galicia. The teachers were monitored by means of interviews held between 2012 and 2014. Our research belongs to a bigger multifocused study on two homogeneous groups (CLIL and non-CLIL samples, $\mathrm{N}=20$ and $\mathrm{N}=24$ ), in which we analysed the effects of CLIL on all the languages used for learning, on content learning and on the attitudes and motivations of the whole educational community taking part in the programme (see San Isidro \& Lasagabaster, 2018b). The school participating in this study implemented a project with a view to realizing the potential of the CLIL experience, which is why the first author of this article, together with the teachers involved in the project, decided to create pedagogic training modules covering the main areas related to CLIL theory, design and implementation. During the two-year CLIL programme, language interdependence between the different languages was present in the language lessons and teachers collaborated in co-designing the language tasks across the different languages. After being trained, they took part in a CLIL project based on curriculum integration with two different groups of students.

Our study was designed with a view to analyse the participating teachers' views on:

RQ1: CLIL impact on students' attitudes and motivations towards language learning.

RQ2: CLIL impact on parents' attitudes and motivations towards language learning.

RQ3: CLIL implementation.

RQ4: CLIL impact on foreign language learning.

RQ5: CLIL impact on L1 learning.

RQ6: CLIL providing a framework for language learning on a plurilingual basis.

RQ7: CLIL impact on content learning.

RQ8: CLIL impact on student's code-switching.

Our primary goal was to ascertain whether the main interests and concerns for practitioners coincide with the ones for researchers, analysed in the introduction above.

\section{Method}

Since the CLIL project analysed in this study was based on curriculum integration and the collaboration of the different language teachers, the sample was a representation of it: one teacher of Galician, one teacher of Spanish, two teachers of Social Science and two teachers of English. All of the teachers involved were female, with more than 15 years of teaching experience and their age ranges were 41-50 and 51-60. They were interviewed three times over the two years of the project with a view to observing their perceptions on a longitudinal basis. Teachers gave their views and opinions on CLIL in three different moments: before the start of the programme at the beginning of September 2012; in June 2013; and in June 2014. Open questions were used in the interviews, which we recorded through the app Voice Record and later transcribed for analysis using the software Atlas.ti. Frequently chosen as a data-collecting technique because of their various advantages, recorded interviews typically produce detailed accounts from respondents and the researcher can exploit the interactive nature of the interview to better understand the informants' responses (Garrett, Coupland, \& Williams, 2003). Although "interviews are extremely time-consuming and difficult to administer" (Bryman, 2004, p. 133), we decided to use them because the sample was small and transcription would not be so tedious. Interviews were recorded (total recording time was 180 minutes) and transcribed. In-depth notes were taken regarding participants' opinions, noting down possible categories for later coding. 
These were the questions as posed in the different moments:

- QUESTION 1:

- Considering what is happening with CLIL in Galicia, which are the positive aspects you can see in CLIL implementation at the moment? (September 2012)

- After one year in CLIL, which are the positive aspects you could see in CLIL implementation? (June 2013)

- After two years in CLIL, which are the positive aspects you could see in CLIL implementation? (June 2014)

\section{- QUESTION 2:}

- We are going to start implementing CLIL in our school. Which are the negative aspects you can see in CLIL implementation at the moment? (September 2012)

- After one year in CLIL, which are the negative aspects you could see in CLIL implementation? (June 2013)

- After two years in CLIL, which are the negative aspects you could see in CLIL implementation? (June 2014)

\section{- QUESTION 3:}

- Do you think the students' communicative competence in the three languages is going to change? (September 2012)

- After one year in CLIL, which changes - in terms of students' communicative competence in the three languages - could you identify? (June 2013)

- After two years in CLIL, which changes - in terms of students' communicative competence in the three languages - could you identify? (June 2014)

- QUESTION 4 (only asked in 2014):

- Do you think CLIL implementation should go on? Why?

Questions were mostly open so as to elicit opinions and occurrences related to the topics in sections 1.3. above (RQ1 to RQ8) in an unguided way.

\section{Results and Discussion}

We will now interpret and describe the significance of the teachers' views. The discussion will be based on triangulation of data as it will be connected to the research study mentioned above (see San Isidro \& Lasagabaster, 2018b), where students' results were measured on a longitudinal quantitative basis. In order to code the data semantically we used the software Atlas.ti, a workbench for the qualitative analysis of large bodies of textual, graphical, audio and video data.

Coding was related to four different categories:

1) CLIL impact on attitudes, students results and code-switching. In order to represent this category, we used the following elements: research questions $[\mathrm{RQ} 1, \mathrm{RQ} 2, \mathrm{RQ} 3 \ldots]+$ positive or negative $[+][-]$ depending on the teachers' view + year $[y y]+$ number.

2) Teachers' collaboration and common design: integrated common design $[\mathrm{ICD}]+$ positive or negative $[+][-]$ depending on the teachers' view + year $[y y]+$ number.

3) Teacher training as an instrumental part in the teachers' view: teacher training [TT] + positive or negative $[+][-]$ depending on the teachers' view + year $[y y]+$ number.

4) Support from the Education Department: $[\mathrm{AS}]+$ positive or negative $[+][-]$ depending on the teachers' view + year [yy] + number.

In the following sections coded excerpts from the transcriptions of the interviews are shown. The sections feature the questions posed in the different moments as well as excerpts of the answers given by the teachers. Some teachers used Galician when answering the questions. In those cases, a translation into English is provided.

\subsection{Teacher 1}

Teacher 1 was a 47-year-old female teacher of Galician with no previous experience in the multilingual approach to language learning. Together with all language teachers, she played an active role in designing a multilingual model for both groups. In our CLIL project, we considered it instrumental to link foreign language learning to L1 learning with a view to 1) making students perceive language learning from a general perspective, i.e. learn all 
languages in the same way and develop a plurilingual competence; and 2) putting the minority language on a par with the majority languages in the curriculum. Answers to the four questions are shown below:

\subsubsection{Question 1}

\section{Excerpt September 2012:}

Translation: I do not agree very much with this approach [RQ6-122], but it is my colleagues' willingness to innovate that has made me take part. I do hope we will attain those benefits researchers talk about so much. It remains to be seen if those benefits can be attained with our kids in a rural school in Galicia.

\section{Excerpt June 2013:}

Translation: The truth is that it has been a fantastic year. Our students have learned a lot, travelled, etc. We, the teachers involved, learned how to collaborate, to design together and to assess in an integrated way [ICD+135]. The truth is that I never would have thought that we would have been able to do it.

\section{Excerpt June 2014:}

Translation: It has been a really positive experience in general terms for both the learners' [RQ1+141] [RQ3+141] [RQ4+141][RQ5+141] [RQ6+141] [RQ7+141] learning skills and the teachers' [TT+144]. We have learned so much!

As regards question number 1 about positive aspects in CLIL implementation, from her initial disbelief, misgivings and preconceptions before starting the project, her views changed towards supporting collaboration, common design and assessment one year later - $[\mathrm{ICD}+135]$ - After two years of implementation, she turned to even more positive views regarding CLIL effects on teachers' - $[\mathrm{TT}+144]$ - and students' attitudes - [RQ1+141] — and results in relation to languages and content-[RQ1+141], [RQ3+141], [RQ4+141],[RQ5+141], [RQ6+141] and [RQ7+141]-.

\subsubsection{Question 2}

\section{Excerpt September 2012:}

Translation: In the schools where it is being implemented the usual thing is for students to be separated [meaning that CLIL groups are normally academically better] and for teachers not to be trained [TT-121].

\section{Excerpt June 2013:}

Translation: The only negative thing in our school is not having enough time to meet and coordinate things. Everything is up to us [AS-131].

\section{Excerpt June 2014:}

Translation: Despite 'giving away' our time to the administration [criticising the Education Department here] [AS-141], if we analyse our students' results [RQ1+142] [RQ3+142] [RQ4+142][RQ5+142] [RQ6+142] [RQ7+142] as well as how much we have learned [TT+145], I can't say anything negative.

With regard to question number 2 and prior to starting the CLIL project, teacher 1 addressed issues such as the lack of teacher training - [TT - 121] — and the fact that CLIL students used to be academically better. After year one, the only negative thing about the programme she could identify was related to the lack of support on the part of the Education Department - [AS - 131] —. In June 2014, when asked the same question, she identified again the lack of support from government administration - [AS - 141] - Nonetheless, she insisted on the positive effects of CLIL on 1) the students' attitudes and motivations, language development and content learning - [RQ1+142], [RQ3+142], [RQ4+142], [RQ5+142], [RQ6+142] and [RQ7+142]—; and 2) teachers' learning - $[\mathrm{TT}+145]$ -

\subsubsection{Question 3}

\section{Excerpt September 2012:}

Translation: I think CLIL won't affect the environmental languages [RQ5-121], but I believe that the students will improve their competence in English [RQ4+121].

\section{Excerpt June 2013:}

Translation: After a year doing tasks relating all languages [ICD+132], there is no doubt that students have improved their language and content related skills [RQ4+131] [RQ5+131] [RQ6+131] [RQ7+131].

\section{Excerpt June 2014:}


Translation: Significant improvement in the three languages, both in the oral and the written medium[RQ4+143] [RQ5+143] [RQ6+143]. The fact that teachers design together works[ICD+142].

Regarding question number 3, teacher 1 showed her disbelief about the students improving their competence in L1 - [RQ5-121] - although she claimed that CLIL students would improve their communicative competence in English - [RQ4+121] —. After year one and year two, her views changed completely as she stated that CLIL students had improved competence in the three languages as well as in content learning-[RQ4+131], [RQ5+131], [RQ6+131] and [RQ7+131] - When interviewed in 2013 and 2014, she put students' improvement down to teacher's collaboration and common design - [ICD+132] and [ICD+142]-.

\subsubsection{Question 4}

\section{Excerpt June 2014:}

Translation: I think it will. We have to get rid of preconceptions. When implemented correctly and provided teachers are trained and language teachers meet regularly to coordinate and design together, learning for both students —language and content wise - and teachers is huge [ICD+142] [RQ4+144] [RQ5+144] [RQ6+144] [RQ7+143]. CLIL improves relations among the teachers because they work in a different way.

Her answer to question number 4 reiterated the same view: students' general improvement in all languages, i.e. development of pluriliteracies, and in content learning in connection to teachers' methodology - [ICD+142], [RQ4+144], [RQ5+144], [RQ6+144] and [RQ7+143]- .

\subsection{Teacher 2}

Teacher 2 was a 52-year-old female teacher of English with no previous experience in either CLIL or a multilingual approach to language learning. Her role was that of being a coordinator for both groups of students in year one. In our CLIL project, a subject teacher - Social Science teacher in our project- and a language specialist - an English teacher in our programme - worked together as a tandem. The English teacher's role is that of a coordinator mentoring the subject teacher as regards integrating language through content and cognition, i.e. in adapting or adjusting language to content and cognition. Her views regarding CLIL implementation changed in the course of time towards more positive opinions about students' language and content related results as well as teachers' collaboration as shown below:

\subsubsection{Question 1}

\section{Excerpt September 2012:}

I am going to face integrated design for the first time and feel really excited about it. We have been told that there are lots of positive effects. So far, we have enjoyed wonderful training sessions [TT +121$]$ and collaboration seems feasible [ICD+121].

\section{Excerpt June 2013:}

The students' improvement in using English (above all, orally) has been spectacular [RQ4+132]. Working with my colleagues has been the best [ICD+133].

\section{Excerpt June 2014:}

CLIL studens have enjoyed the opportunity to develop their capacity to interrelate their skills in a new way and they feel more confident and excited when using English and the other languages [RQ4+145] [RQ5+145] [RQ6+145].

As regards question 1 and despite her lack of experience, teacher 2 seemed quite motivated and showed really positive attitudes towards the project back in 2012 regarding the initial teacher training received prior to the start of the CLIL programme - $[\mathrm{TT}+121]$ - as well as about her readiness to collaborate with the other teachers - [ICD+121]-. After year one, she claimed that students had improved their oral use of English - $[\mathrm{RQ} 4+132]$ - and expressed her satisfaction about team work - $[\mathrm{ICD}+133]$ - By the end of the programme, she stated that CLIL students had developed and improved their capacity for using the different languages $-[\mathrm{RQ} 4+145],[\mathrm{RQ} 5+145]$ and $[\mathrm{RQ6}+145]-$.

\subsubsection{Question 2}

\section{Excerpt September 2012:}

In other schools the non-CLIL students are the worst students result-wise.

\section{Excerpt June 2013:}

Nothing negative, really. 


\section{Excerpt June 2014:}

Nothing negative. Students have developed so many skills and their communicative competence has improved so much that I would do this again a million times [RQ4+146] [RQ5+146] [RQ6+146].

When she was asked about the negative aspects in CLIL implementation, she went from what she thought was happening in other schools implementing CLIL - CLIL students used to be academically better - to finding nothing negative by reiterating the benefits of CLIL for language learning - $[\mathrm{RQ} 4+146]$, [RQ5+146] and [RQ6+146]-.

\subsubsection{Question 3}

\section{Excerpt September 2012:}

I do believe the students in the CLIL group will improve their communicative competence in English [RQ4+122], although I doubt whether they will improve it in Galician or Spanish [RQ5-122].

\section{Excerpt June 2013:}

Contrary to what I expected at the beginning of the project, students' improvement of oral and written skills in the three languages has taken place [RQ4+133] [RQ5+132] [RQ6+132].

\section{Excerpt June 2014:}

They are now more aware of the differences and similarities between the languages and consequently more confident when using them. Massive improvement! [RQ4+147] [RQ5+147] [RQ6+147]

Regarding question 3, she corroborated her initial views regarding English learning both in 2013 and 2014 - [RQ4+147], [RQ5+147] and [RQ6+147]—. On the other hand, her initial disbelief about the positive effects of CLIL on L1 learning gave way to stating that the students had developed a plurilingual competence - [RQ4+147], [RQ5+147] and [RQ6+147]-.

\subsubsection{Question 4}

\section{Excerpt June 2014:}

Definitely yes. It gives a sense of "usefulness" to the additional language which significantly improves its learning. It also makes the students reflect on all the languages they use, which can only benefit their performance in all the subjects [RQ4+148] [RQ5+148] [RQ6+148] [RQ7+144]

As regards question number 4 in 2014, she claimed that students had improved not only their communicative competence in all languages, i.e. development of pluriliteracies, but also their performance regarding content learning - [RQ4+148], [RQ5+148], [RQ6+148] and [RQ7+144]-.

\subsection{Teacher 3}

Teacher 3 was the Social Science teacher in year one. She was 48 years old and had developed CLIL programmes previously. The subject teacher taught both groups using different vehicular languages: Galician was used with the non-CLIL students and English was the language used with the CLIL group. The methodology used was the same with both groups. The only difference was the vehicular language used for teaching Social Science.

\subsubsection{Question 1}

\section{Excerpt September 2012:}

Translation: This is not the first time I have taken part in an experience like this. I know the positive aspects for kids as well as for teachers. My expectations are high this time.

\section{Excerpt June 2013:}

Translation: Learning content through a foreign language and designing tasks with teachers of other languages [ICD+134], putting all kinds of learning in relation was an enriching experience for the kids and for us.

\section{Excerpt June 2014:}

Translation: The students developed their ability to use a foreign language in academic contexts. They were able to use it in order to search for, organise and transmit information as well as apply the strategies they previously used with Galician or Spanish [RQ4+149]. 
As regards question 1, teacher 3 expressed her positive views from the very beginning. This was related to her previous experience. Her answers to question 1 stated the benefits of CLIL regarding foreign language learning $-[\mathrm{RQ} 4+149]$ - on the grounds of teachers' collaboration and common design $-[\mathrm{ICD}+134]-$.

\subsubsection{Question 2}

\section{Excerpt September 2012:}

Translation: I think previous teacher training [TT+122] is necessary to develop appropriate CLIL-related methodologies. When this is not the case (something that frequently happens), teachers just replicate what they do in L1-based lessons.

\section{Excerpt June 2013:}

Translation: We had to take on our personal time to coordination and common design. The Education Department should provide us with specific times to do so [AS-132].

\section{Excerpt June 2014:}

Translation: After two years given the results attained, I cannot mention anything being negative. Well, we need more support from the Education Department [AS-142].

As regards question 3, she claimed that teacher training was instrumental for CLIL implementation to be successful - $[\mathrm{TT}+122]$ - After year one, the only negative thing about the programme she could identify was related to the lack of support on the part of the Education Department - [AS-132] - In June 2014, when asked the same question, she identified again the lack of support from the government administration -

\subsubsection{Question 3}

\section{Excerpt September 2012:}

Translation: I am certain that there will be an improvement in English [RQ4+123], but I have doubts about the improvement in the other languages [RQ5-123].

\section{Excerpt June 2013:}

Translation: After one year of implementation, I am sure about the improvement in the use of English in Social Science [RQ4+134]. I cannot find any single problem about content learning [RQ7+132]. I cannot assess the other languages.

\section{Excerpt June 2014:}

Translation: As regards English, there's no doubt that students, after two years, are able to understand complex texts about Social Science; do projects on geographical or historical contents using the appropriate language; and, in general, understand the lessons taking an active part in them [RQ4+1410]. With regard to Galician, I cannot see any differences between the CLIL students and the ones doing Social Science in Galician [RQ5+149]. I am afraid I cannot assess their competence in Spanish, as I do not teach my lessons in this language.

Regarding question number 3, teacher 3 showed some misgivings about the students improving their competence in L1 - [RQ5-123] - although she claimed that CLIL students would improve their communicative competence in English - [RQ4+123] —. After year one and year two, her views did not change regarding improvement in the foreign language, as she stated that CLIL students had improved their competence in English - [RQ4+134] and [RQ4+1410]- Her initial doubts about the students' improvement in the other two languages gave way to her seeing no difference between both CLIL and non-CLIL students regarding Galician - $[\mathrm{RQ} 5+149]$ - She claimed that she could not evaluate Spanish as she had not taught Social Science through Spanish. Furthermore, she claimed students had not found any difficulty in learning content through English $-[\mathrm{RQ7+132]-}$.

\subsubsection{Question 4}

\section{Excerpt June 2014:}

Translation: In my opinion, it is important to keep implementing the CLIL approach, because it gives the students the chance to use a second (or third in this case) language in real contexts. English becomes a vehicle for acquisition and transmission of knowledge. The students lose their fear of using the foreign language [RQ1+143] and assume that all languages have the same function: communicative [RQ6+149]. 
Her answer to the final question in 2014 showed her satisfaction and her support for the CLIL model as she claimed students had developed more positive attitudes - [RQ1+143] — as well as they developed a plurilingual competence - [RQ6+149]-.

\subsection{Teacher 4}

Teacher 4 was a 41-year-old female teacher of Spanish with a lot of experience in multilingual programmes related to the integrated treatment of languages (i.e. translanguaging). Together with all language teachers, she played an active role in designing a pluriliteracy-oriented model for both groups. As explained above, in our CLIL project, we linked foreign language learning to L1 learning with a view to 1) making students develop a plurilingual competence; and 2) putting the minority language - Galician — on a level with the majority languages in the curriculum - Spanish and English - Answers to the four questions are shown below:

\subsubsection{Question 1}

\section{Excerpt September 2012:}

Translation: CLIL is said to improve students' language competence [RQ4+124] [RQ5+121] [RQ6+121] as well as it provides new ways of lesson-designing, using technology and, most importantly, working in a cross-curricular way and through project work [RQ3+121].

\section{Excerpt June 2013:}

Translation: A global improvement in [the students'] communicative competence in the three languages. Work on a plurilingual basis is worthwhile [RQ6+133].

\section{Excerpt June 2014:}

Translation: [CLIL] improves the students' communicative competence, both in the foreign language and the other languages, because it allows transference and avoids duplication and redundancies among the different language subjects [RQ6+1410].

Teacher 4's views were consistent from the very beginning of the project. According to her opinions, the main positive effects of CLIL were related to the students' development of a pluriliteracies - [RQ4+124], [RQ5+121], [RQ6+121], [RQ6+133] and [RQ6+1410] - She stated that students had improved their communicative competence in the three languages as CLIL and the multilingual approach had allowed transference and avoided duplication and redundancies among the different languages as subjects.

\subsubsection{Question 2}

\section{Excerpt September 2012:}

Translation: Although it is not the case in our school, the approach adopted by other schools is not really CLIL as it is limited to learning vocabulary lists in a foreign language in a content subject [RQ3-121].

\section{Excerpt June 2013:}

Translation: Not a negative thing, except for the fact that the Education Department does not provide us with the necessary times and spaces for this model of curriculum integration [AS-133].

\section{Excerpt June 2014:}

Translation: Nothing negative.

As regards question 2, prior to the start of the project back in 2012 she negatively referred to issues such as vocabulary memorisation as a strategy for content learning in other schools - [RQ3-121] - After year one, the only negative thing about the programme she could identify was related to the lack of support on the part of the Education Department - [AS_-133] —. In June 2014, when asked the same question, she did not mention a single negative thing about CLIL implementation.

\subsubsection{Question 3}

\section{Excerpt September 2012:}

Translation: I do not really know if CLIL will have an impact on the co-official languages in Galicia, apart from English.

\section{Excerpt June 2013:}

Translation: This year, after the students having enrolled on CLIL and the teachers having implemented an integrated treatment of languages, there is a significant improvement in the oral and written use of all languages [RQ6+134] [ICD+139]. 


\section{Excerpt June 2014:}

Translation: As regards the group that was enrolled on CLIL for two years, we can observe a higher competence in the three languages probably due to the integrated treatment of languages since 3ESO [third year of compulsory secondary education][RQ6+1411] [ICD+147].

Regarding question 3 about the impact of CLIL in the three languages, from her initial doubts in 2012, her views became rather positive in both 2013 and 2014. According to her, students seemed to have improved their communicative competence in all languages - $[\mathrm{RQ6}+134]$ and $[\mathrm{RQ} 6+1411]$ - due to the CLIL model and the multilingual approach to language learning, favoured and implemented by all the language teachers involved in the project.

\subsubsection{Question 4}

\section{Excerpt June 2014:}

Translation: Yes, it should go on. I think an integrated approach [ICD+148] is the best way to develop the students' language competence. Languages are instrumental in acquiring knowledge in the different areas. This is the reason why students improve knowledge in the different content and language areas when CLIL is implemented [RQ6+1412] [RQ7+145].

Her answer to question 4 in 2014 summed up her views on the benefits of CLIL: provided teachers collaborated and designed together - $[\mathrm{ICD}+148]$ — students could develop and improve their plurilingual competence $-[\mathrm{RQ6}+1412]$ - as well as their content learning - [RQ7+145]-.

\subsection{Teacher 5}

Teacher 5 was the Social Science teacher in year two. She was 54 years old and had no previous experience in CLIL programmes. These are some excerpts of teacher 5's answers to the four questions:

\subsubsection{Question 1}

\section{Excerpt September 2012:}

I do think CLIL will give us the chance to work differently [RQ3+122] and the students will develop a better communicative competence [RQ6+122].

\section{Excerpt June 2013:}

Wonderful results, improvement of students' competence in the three languages [RQ6+135], collaboration, joint integrated design, project work...[ICD+135]

\section{Excerpt June 2014:}

Curriculum integration, collaboration, joint design... [ICD+143]. The fact that it can be used with ALL students makes it amazing [RQ3+143].

Her initial positive views - $[\mathrm{RQ} 3+122]$ and $[\mathrm{RQ} 6+122] —$ were sustained in the course of time $-[\mathrm{RQ} 3+143]-$. According to her, students had improved their competence in the three languages. This improvement seemed to be directly connected to teachers' methodology, based on curriculum integration, common design or collaboration - $[\mathrm{RQ} 6+135]$ and $[\mathrm{ICD}+143]-$.

\subsubsection{Question 2}

\section{Excerpt September 2012:}

Lack of pedagogical training [TT-122]. A good competence in the foreign language does not guarantee the quality of the project, because CLIL teachers MUST be trained methodologically.

\section{Excerpt June 2013:}

After a year collaborating with colleagues [ICD+136], I cannot say a single negative thing about the project. At the beginning I had doubts about our own training. But the training modules plus the constant cooperation has made me learn a lot of things from a professional perspective [TT+131].

\section{Excerpt June 2014:}

When CLIL is implemented the way we have done it (previous teacher training, perfect cross-curricular planning, task-based and project-based learning, travelling abroad...) talking about something negative about this well-planned programme would be unfair [TT+141] [ICD+144] [RQ3+144]. 
As regards the question related to negative aspects, teacher 5 identified a key aspect: the lack of teacher training - [TT - 122] - . Over the two years, her positive views - [RQ3+144] — about CLIL implementation had to do with a careful planning and design - $[\mathrm{ICD}+136]$ and $[\mathrm{ICD}+144]$ - as well as with the previous teacher training - $[\mathrm{TT}+131]$ and $[\mathrm{TT}+141]$ -

\subsubsection{Question 3}

\section{Excerpt September 2012:}

CLIL is going to make an impact in the students' competence in English [RQ4+125]. The English teachers are going to work with the other language teachers (Galician and Spanish) and we, the content teachers are contributing to that in our area [ICD+122]. Hopefully results will be positive.

\section{Excerpt June 2013:}

I think that, after this year, all teachers involved have wowed at the improvement of students' communicative skills in the three languages [RQ6+136]. No problem found in content learning either [RQ7+133].

\section{Excerpt June 2014:}

The unquestionable improvement in the three languages, regarding both oral and written skills [RQ6+1413].

With regard to question 3, her opinions were positive from the very beginning referring to teachers' collaboration as the lynchpin - $[\mathrm{ICD}+122]$ - According to her, CLIL students developed and improved a plurilingual competence - $[\mathrm{RQ} 6+136]$ and $[\mathrm{RQ} 6+1413]$ — and did not find any difficulty in learning content through English - $[\mathrm{RQ7+133]-}$.

\subsubsection{Question 4}

\section{Excerpt June 2014:}

Yes! If done well (previous training, appropriate monitoring, commitment and collaboration) it is a wonderful approach for language and content learning [TT+142] [ICD+149] [RQ3+145] [RQ6+1416] [RQ7+147].

Her answer to question 4 in 2014 revealed her positive views - [RQ3+145] — on the benefits of CLIL. Under the appropriate circumstances, i.e. previous training, monitoring, commitment and collaboration, CLIL would be a perfect approach to learn language and content - [TT+142], [ICD+149], [RQ6+1416] and [RQ7+147]-.

\subsection{Teacher 6}

Teacher 6 was a 60-year-old female teacher of English with extensive experience in CLIL. Her role was that of being a coordinator for both groups of students in year two. These are some excerpts of teacher 6's answers to the four questions:

\subsubsection{Question 1}

\section{Excerpt September 2012:}

Translation: I believe that, if we work well, we can make our students attain a lot of educational benefits: global learning, improvement in the different languages, etc. We, as teachers, will learn lots of things too, because we will work together designing tasks and projects [ICD+123].

\section{Excerpt June 2013:}

Translation: Improvement in [the three] languages, learning through a global approach, teacher collaboration...[RQ6+137] [RQ3+131] [ICD+137]

\section{Excerpt June 2014:}

Translation: Common design, collaboration among the different language [teachers], cross-curricular tasks and projects...The impact on the languages and other content is huge [ICD+145] [RQ3+146] [RQ6+1414] [RQ7+146].

Teacher 6 identified the sine qua non for CLIL success at the very start: collaboration, common design, global learning - $[\mathrm{ICD}+123]$ - Her views were consistent throughout the development of the programme - [ICD+137] and [ICD+145] - and, after year one and year two, she claimed students had improved not only their competence in the three languages $-[\mathrm{RQ6}+1414]$ — but also their content learning $-[\mathrm{RQ7}+146]-$.

\subsubsection{Question 2}

\section{Excerpt September 2012:}

Translation: The Xunta de Galicia does not provide the necessary training [TT_122] [AS_-121]. Training must 
be both language-oriented and pedagogical and methodological. Starting a project like this is hard work and depends on the teachers' willingness.

\section{Excerpt June 2013:}

Translation: The only negative thing is our lack of time sometimes. However, given the results, it is worth it.

\section{Excerpt June 2014:}

Translation: I have to say that the only thing I missed was the lack of support from the Education Department [AS-143]. As regards the programme, there was nothing negative.

As regards question 2, she identified two negative points related to CLIL implementation: the lack of teacher training - [TT - 122] — and the lack of support on the part of the government administration — [AS - 121] After two years in the programme, the only negative thing she could identify was related to the lack of support on the part of the Education Department - [AS - 143] -

\subsubsection{Question 3}

\section{Excerpt September 2012:}

Translation: This is new for me and and have some fears and doubts. I do not know whether the results will be positive or not. Everything will be dependent on our commitment to the project.

\section{Excerpt June 2013:}

Translation: The initial training prior to the project was instrumental [TT+132] and, after working together designing tasks and integrating Social Science [ICD+138], I can only say that the improvement of the students' communicative competence is evident [RQ6+138].

\section{Excerpt June 2014:}

Translation: The overall improvement in the students' plurilingual competence [RQ6+1415].

With regard to question 3 about the impact of CLIL on language learning, after her initial doubts back in 2012, her views turned really positive after year one and year two. According to her, students had undergone an overall improvement of their competence in the three languages - [RQ6+138] and $[\mathrm{RQ} 6+1415]-$. This overall improvement had to do with the fact that 1) participating teachers were previously trained - [TT+132] -; and 2) their methodology was based on collaboration and common design - [ ICD +138$]-$.

\subsubsection{Question 4}

\section{Excerpt June 2014:}

Translation: CLIL is a good strategy when it is well understood and its design is based on collaboration as well as related to all languages and project work $[\mathrm{ICD}+146]$. The kind of CLIL we implement in our school is inclusive and it is implemented by teachers who were trained to do so [TT +143$]$.

Her answer to question 4 in 2014 reiterated the same idea. In order for CLIL to be successful, teachers had to be trained - $[\mathrm{TT}+143]$ — and their methodology had to be based on collaboration as well as on integrating different kinds of learning through project work - $[\mathrm{ICD}+146]-$.

\subsection{Final Comments}

After the description of the six teachers' answers, the coding and analysis of those answers (see codes above) revealed the following number of occurrences, divided in positive - number on the left- and negative - number on the right -

Table 1. Occurrences in the qualitative analysis of teachers' views

\begin{tabular}{lllllllllll}
\hline RQ1 & RQ2 & RQ3 & RQ4 & RQ5 & RQ6 & RQ7 & RQ8 & ICD & TT & AS \\
\hline $\mathbf{1 6} \mid \mathbf{0}$ & $0 \mid 0$ & $\mathbf{1 7} \mid \mathbf{1}$ & $\mathbf{3 8} \mid \mathbf{0}$ & $\mathbf{2 2} \mid \mathbf{2}$ & $\mathbf{4 9} \mid \mathbf{3}$ & $\mathbf{1 0} \mid \mathbf{0}$ & $0 \mid 0$ & $\mathbf{4 3} \mid \mathbf{0}$ & $\mathbf{1 7 | 5}$ & $\mathbf{0} \mid \mathbf{1 8}$ \\
\hline
\end{tabular}

Teachers' answers did not show any occurrences in relation to research questions RQ2 and RQ8. Those research questions were the ones related to parents' attitudes and motivations, along with code-switching. Since the participants were not directly asked about parents' attitudes and code-switching, it could be concluded that these two issues do not seem to represent their main concerns, although they seem to be a niche for research 
(Pladevall-Ballester, 2015; San Isidro \& Lasagabaster, 2018a). Nonetheless, qualitative data elicited from teachers' answers seemed to converge into the following aspects:

- Teachers seemed to agree on CLIL students' improvement attitudes towards language learning - [RQ1]Their perceptions on implementation - [RQ3] — became gradually more favourable in the course of time.

- According to teachers' views, CLIL seem to be related to the development of pluriliteracies, i.e. students seemed to improve their competence in the three languages - [RQ4], [RQ5] and [RQ6]. These views coincide with the students' results analysed by San Isidro and Lasagabaster (2018b).

- $\quad$ Regarding content learning - [RQ7] - a lower number of occurrences in the six participating teachers's answers showed a less clear opinion on the positive effect of CLIL on content learning. Comparing these views with students' results analysed by San Isidro and Lasagabaster (2018b), the number of occurrences seem to point in the same direction, i.e. a neutral effect of CLIL on content learning.

- Teachers seemed to agree on collaborative methodology and curriculum design - [ICD] — as the basis for a successful implementation of CLIL. Integration as well as its impact on classroom practice were at the core of the pedagogical part in our project. During the two-year CLIL programme, translanguaging - [RQ6] — was present in the pluriliteracy-oriented language lessons since language teachers designed together, and language tasks were similar in the different languages.

- Teachers' views seemed to converge into two more things: on the one hand, the need for teacher training prior to starting any CLIL programme - $[\mathrm{TT}]$ — and, on the other hand, the lack of support from the Education Department - $[\mathrm{AS}]$ -

The findings reported in this study have shed some light on teachers' views on the relationship between CLIL and curriculum integration; and on the connection existing between teacher training, collaborative methodology and implementation. Our research has also shown that participating teachers think that integration-based classroom practices make a massive impact on how they work, and that such integration should be a key feature of any CLIL programme that intends to lead to effective teaching, high standards and successful learning.

This particular CLIL experience happened to be successful due to the enormous commitment on the part of the teachers involved. It should be borne in mind that this is not an easy objective to achieve, which is why the recurrent demand from the participants regarding a greater involvement of the Education Department should not go unnoticed. Not all schools may be so willing to make such grass roots and strenous efforts if they do not receive support from the administration.

\section{Acknowledgments}

This work is supported by the Spanish Ministry of Economy and Competitiveness (grant numbers MINECO FFI2012-34214 and FFI2016-79377-P, AEI/FEDER, UE) and the Basque Government (grant number IT904-16).

\section{References}

Ackerl, C. (2007). Lexico-grammar in the essays of CLIL and non-CLIL students: Error analysis of written production. Vienna English Working Papers, 16(3), 6-11.

Ball, P., Kelly, K., \& Clegg, J. (2015). Putting CLIL into practice. Oxford: Oxford University Press.

Barreiro, I., \& San Isidro, X. (2009). Estudo: Perspectiva empírica sobre as aulas CLIL galegas. In X. San Isidro, (Ed.), CLIL: Integrando linguas "a través" do currículo. Santiago de Compostela: Consellería de Educación e Ordenación Universitaria. Xunta de Galicia.

Bruton, A. (2013). CLIL: Some of the reasons why ... and why not. System, 41, 587-597. https://doi.org/10.101 6/j.system.2013.07.001

Bryman, A. (2004). Social Research Methods. Oxford: Oxford University Press. https://doi.org/10.1557/PROC -818-M1.10.1

Calvo, E., \& San Isidro, X. (2012). The fusion effect of CLIL on language-building and content learning: research study. In O. Meyer, \& D. Marsh, (Eds.), Quality Interfaces: Examining Evidence \& Exploring Solutions in CLIL (pp. 103-140). Eichstaett: Eichstaett Academic Press.

Cenoz, J., Genesee, F., \& Gorter, D. (2014). Critical analysis of CLIL: Taking stock and looking forward. Applied Linguistics, 35(3), 243-262. https://doi.org/10.1093/applin/amt011

Coonan, C. M. (2007). Insider views of the CLIL class through teacher self-observation-introspection. International Journal of Bilingual Education and Bilingualism, 10(5), 625-46. https://doi.org/10.21 


\section{7/beb463.0}

Coyle, D. (2006). Motivation and CLIL. Scottish Centre for Language Teaching and Research CILT: Newsletter. Retrieved from http://blocs.xtec.cat/clilpractiques1/files/2008/11/slrcoyle.pdf

Coyle, D. (2007). Content Language Integrated Learning: Towards a Connected Research Agenda for CLIL pedagogies. International Journal of Bilingual Education and Bilingualism, 10(5), 543-562. https://doi.org /10.2167/beb459.0

Coyle, D., Hood, P., \& Marsh, D. (2010). CLIL_Content and Language Integrated Learning. Cambridge: Cambridge University Press.

Cummins, J. (1984). Bilingual Education and Special Education: Issues in Assessment and Pedagogy. San Diego: College Hill.

Czura, A., Papaja, K., \& Urbaniak, M. (2009). Bilingual education and the emergence of CLIL in Poland. In D. Marsh, P. Mehisto, D. Wolff, R. Aliaga, T. Asikainen, M. J. Frigols-Martín, S. Hughes, \& G. Langé (Eds.), CLIL practice: Perspectives from the field (pp. 172-178). Finland: University of Jyväskylä.

Garrett, P., Coupland, N., \& Williams, A. (2003). Investigating Language Attitudes Social Meanings of Dialect, Ethnicity and Performance. Cardiff: University of Wales Press.

Hofler, D. B. (2010) Approach, method, technique a clarification. Reading World, 23(1), 71-72. https://doi.org/10.1080/19388078309557742

Infante, D., Benvenuto, G., \& Lastrucci, E. (2009). The effects of CLIL from the perspective of experienced teachers. In D. Marsh, P. Mehisto, D. Wolff, R. Aliaga, T. Asikainen, M. J. Frigols-Martín, S. Hughes, \& G. Langé (Eds.), CLIL practice: Perspectives from the field (pp. 156-163). Finland: University of Jyväskylä.

Lasagabaster, D., \& Doiz, A. (2017). A Longitudinal Study on the Impact of CLIL on Affective Factors. Applied Linguistics, 38(5), 688-712.

Lorenzo, F., Casal, S., \& Moore, P. (2010). The effects of content and language integrated learning in European education: Key findings from the Andalusian bilingual sections evaluation project. Applied Linguistics, 31(3), 418-442. https://doi.org/10.1093/applin/amp041

Loureiro-Rodríguez, V., Bogess, M., \& Goldsmith, A. (2013). Language attitudes in Galicia: Using the matched-guise test among high school students. Journal Of Multilingual And Multicultural Development, 34(2), 136-153. https://doi.org/10.1080/01434632.2012.729591

Marsh, D., Coyle, D., Kitanova, S., Maljers, A., Wolff, D., \& Bronislawa, Z. (2005). Project D3 - CLIL Matrix. The CLIL quality matrix. Central Workshop Report 6/2005. Retrieved from http://archive.ecml.at/mtp 2/clilmatrix/pdf/wsrepD3E2005_6.pdf

Mehisto, P., \& Asser, H. (2007). Stakeholder perspectives: CLIL programme management in Estonia. International Journal of Bilingual Education and Bilingualism, 10(5), 683-701. https://doi.org/10.2 $167 /$ beb466.0

Mehisto, P., Marsh, D., \& Frigols, M.J. (2008). Uncovering CLIL: Content and Language Integrated Learning in Bilingual and Multilingual Education. Oxford: Macmillan.

Nandi, A., \& Devasundaram, A.I. (2017). Contesting the Conventionalising of Castilian: The Role of Galician Parents as Counter-Elites. In F. Lauchlan, \& M. C. Parafita Couto (Eds.), Bilingualism and Minority Languages in Europe: Current trends and developments (pp. 12-33). Newcastle upon Tyne: Cambridge Scholars Publishing.

Pérez Cañado, M. L. (2016). From the CLIL craze to the CLIL conundrum: addressing the current CLIL controversy. Bellaterra: journal of teaching and learning language and literature, 9(1), 9-31. https://doi.org/10.5565/rev/jtl3.667

Pladevall-Ballester, E. (2015). Exploring primary school CLIL perceptions in Catalonia: students', teachers' and parents' opinions and expectations. International Journal of Bilingual Education and Bilingualism, 18(1), 45-59. https://doi.org/10.1080/13670050.2013.874972

San Isidro, X. (2017). Mainstreaming CLIL? The Galician case. In C. Tremblay, \& J. C. Beacco (Eds.), Plurilinguisme et éducation. Collection Plurilinguisme 2017. Volume 2. L'Observatoire Européen du Plurilinguisme. Bookelis.

San Isidro, X. (2018). Innovations and challenges in CLIL implementation in Europe. Theory into Practice. 
Special Issue. https://doi.org/10.1080/00405841.2018.1484038

San Isidro, X. \& Lasagabaster, D. (2018a). Code-switching in a CLIL multilingual setting: a longitudinal qualitative study. International Journal of Multilingualism. https://doi.org/10.1080/14790718.2018.1477781

San Isidro, X., \& Lasagabaster, D. (2018b). The impact of CLIL on pluriliteracy development and content learning in a rural multilingual setting: A longitudinal study. Language Teaching Research. https://doi.org/10.1177/1362168817754103

Wiesemes, R. (2009). Developing theories of practices in CLIL: CLIL as post-method pedagogies? In Y. Ruiz de Zarobe, \& R. M. Jiménez Catalan (Eds.), Content and language integrated learning. Evidence from research in Europe (pp. 41-59). Bristol: Multilingual Matters.

\section{Copyrights}

Copyright for this article is retained by the author(s), with first publication rights granted to the journal.

This is an open-access article distributed under the terms and conditions of the Creative Commons Attribution license (http://creativecommons.org/licenses/by/4.0/). 